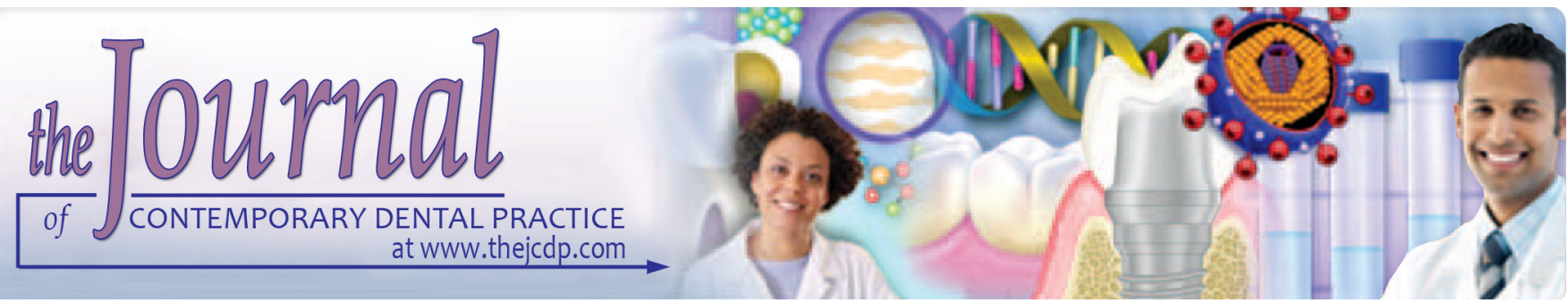

\title{
Assessment of Enamel Surface Microhardness with different Fluoride Varnishes-An In Vitro Study
}

\author{
${ }^{1}$ Sameer Punathil, ${ }^{2}$ Civy V Pulayath, ${ }^{3}$ Siraj P Ismail, ${ }^{4}$ Shashit S Bavabeedu, ${ }^{5}$ Shabna Moyin, ${ }^{6}$ Roshan Uthappa
}

\section{ABSTRACT}

Aim: This study aimed to assess the microhardness of the enamel surface after fluoride varnish application.

Materials and methods: Thymol of $0.1 \%$ in distilled water was used to store the collected healthy sixty teeth. The samples were divided into three groups randomly as per the different application of fluoride varnish. Group A: Fluor protector varnish (FIV) application, group B: Duraphat varnish application and group C: Bifluorid 10 varnish application. The present study followed the $\mathrm{pH}$ cycling protocol. Microhardness tester was used to test the microhardness of enamel surface and was expressed as microhardness measurements of Vickers hardness number (VHN) which was performed at baseline, on the 3rd day andon 7 th day.

Results: At baseline, group A samples mean $\mathrm{SMH}$ value was $230.64 \pm 12.32$ which was slightly more than groupB with $229.45 \pm 10.22$ and group $C$ with $230.10 \pm 11.45$. There was no significant difference showed with the analysis of variance between the groups. On the 3rd day, there was a slight increase in the mean SMH in group A with $235.39 \pm 6.44$ and no significant difference between the groups was seen statistically. On the 7 th day, the group A showed high SMH value of $262.20 \pm 4.89$ compared to other groups which didn't show a significantly high statistical difference.

${ }^{1}$ Department of Pediatric and Preventive Dentistry, Sree Anjaneya Institute of Dental Sciences, Calicut, Kerala, India

${ }^{2}$ Department of Public Health Dentistry, Malabar Dental College and Research Centre, Edappal, Kerala, India

${ }^{3}$ Department of Public Health Dentistry, Pariyaram Dental College, Pariyaram, Kannur Kerala, India

${ }^{4}$ Restorative Dental Sciences, King Khalid University College of Dentistry, Abha, Kingdom of Saudi Arabia

${ }^{5}$ Department of Conservative dentistry and Endodontics, Sree Anjaneya Institute of Dental Sciences, Calicut, Kerala, India

${ }^{6}$ Department of Restorative Dental Sciences, College of Dentistry, Majmaah University, Al Zulfi, Kingdom of Saudi Arabia

Corresponding Author: Sameer Punathil, Department of Pediatric and Preventive Dentistry, Sree Anjaneya Institute of Dental Sciences, Calicut, Kerala, India, Phone: +919526227454, e-mail: sameeralshifa@gmail.com
Conclusion: On conclusion, post-application of fluorprotector varnish showed higher enamel surface microhardness compared to Duraphat and Bifluorid 10 varnishes.

Clinical significance: In young children, fluoride varnishes are effectively used as a noninvasive, anti-caries agent in the treatment of initial caries. Therefore, in routine dental practice, the knowledge about different fluoride varnishes is of importance.

Keywords: Demineralization, Fluoride varnish, Remineralization, Surface microhardness

How to cite this article: Punathil S, Pulayath CV, Ismail SP, Bavabeedu SS, Moyin S, Uthappa R. Assessment of Enamel Surface Microhardness with different Fluoride VarnishesAn In Vitro Study. J Contemp Dent Pract 2018:19(11): 1317-1321.

Source of support: Nil

Conflict of interest: None

\section{INTRODUCTION}

The tooth surface appearance of a white spot lesion (WSL) is the first clinical sign of dental caries, which can be considered as the initial stage of the demineralization of the enamel. ${ }^{1}$ This initial stage lesion may progress as cavity after a continuous process of demineralization process. Therefore, for maintenance of healthy dentition, an effective and noninvasive treatment is enhancing the early carious lesion's remineralization. ${ }^{2}$

The infectious micro-biological disease which leads to localized destruction and dissolution of the calcified teeth structure is called dental caries. The caries is a disease which is multifactorial, depending on many factors and is a complicated process. ${ }^{3}$ Dental caries is also known as a microbial disease dynamic diet which involves a cyclic process of demineralization and remineralization. The caries early stage can be reversed by eliminating and modifying etiological factors such as diet, and plaque/biofilm and also by increasing in the protective factors such as salivary flow, and fluoride exposure. ${ }^{4}$ 
The effective method to prevent caries is by the application of fluoride varnishes. About 40 to $56 \%$ of caries incidences can be reduced by using varnishes. Fluoride varnish is an adherent material applied professionally consists of the high concentration of fluoride as preparation of silane or salt in fast drying, for natural varnishes as an alcohol-based solution. Varnishes are coated on the enamel surface. The main purpose of using fluoride varnish is to keep the fluoride in contact with the enamel for a prolong period. ${ }^{5}$

The varnish with fluoride covers the enamel surface for 24 hours with its adhesive property. This period increases the fluoride ion absorption into the tooth surface. The deposits of calcium fluoride act as a reservoir for fluoride ions and released slowly. ${ }^{6}$

Fluoride ions can improve the enamel apatite crystallinity. The stability of the enamel apatite is denoted by the crystallinity improvement and persistence of few dislocation and imperfections within the crystals. The net result showed an increase in the stability of the enamel surface substituted lattice even with the fluoride in its low concentration. The fluoride treated enamel reduces the depth of the carious lesion, more acid solubility resistant decreases the rate of demineralization and increases the remineralization rate. ${ }^{7}$

Physical properties can influence the fluoride varnishes activity on the enamel surface. For the effectiveness of preventive measure, the contact time between the fluoride product and the enamel surface plays a very important role; the use of some materials could avoid Floss to saliva and, consequently, improve its anticariogenic effect. Considering the null hypothesis that there is no significant difference between the three varnishes on the enamel surface of the tooth. Therefore this study was conducted with an aim to evaluate the

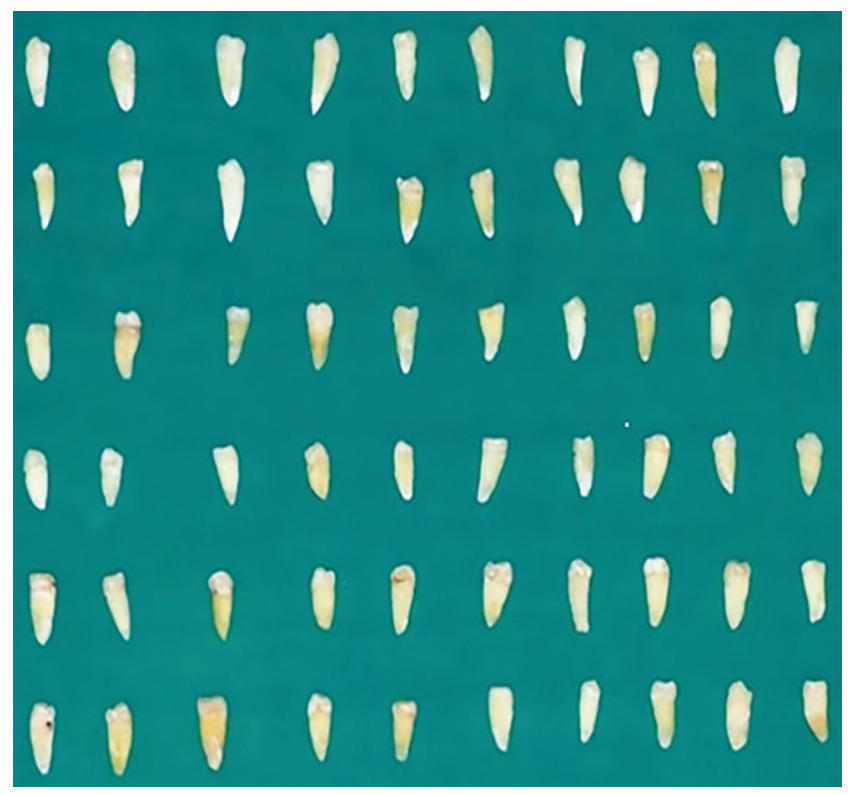

Fig. 1: Samples used in this study microhardness of the enamel surface treated with different types of fluoride varnishes.

\section{MATERIALS AND METHODS}

The present in vitro study was conducted in the Department of Pediatric and Preventive Dentistry, Sree Anjaneya Institute of Dental Sciences, Keralam India.

\section{Specimen Preparation}

Sixty premolars which were healthy and extracted for orthodontic reasons were stored after collecting (Fig. 1). Teeth surface should be intact without any decalcification signs or white spot lesions were included in the study. Using a surface scaler, the deposits of calculus or any soft tissues were removed. Pumice slurry was used to clean the teeth. Thymol of $0.1 \%$ content in the distilled water which inhibits the growth of microorganisms was used as a storage media of the teeth. To obtain $2 \times 2 \mathrm{~mm}$ sectioning of the enamel blocks from the buccal surface of the crown which was a prominent portion, hard tissue microtone of Silverstone-Taylor was used. Polishing grits (\#800, 1000, and 1200) were used to polish and flatten the blocks serially. A smooth flat surface was achieved by embedding the blocks under acrylic blocks.

\section{Baseline Surface Microhardness}

Using the micro-hardness tester machine (Fig. 2); "Shimadzu HMV-2000/Shimadzu Corporation, Kyoto, Japan", each sample's surface micro-hardness (SMH) was initially assessed. Applying a load of $25 \mathrm{mg}$ for 10 seconds an indentation on enamel, SMH was assessed. ${ }^{8}$ The value was noted when displayed on the machine.

\section{Application of Varnishes}

The samples were divided into three groups randomly for 3 types of fluoride varnish application (Fig. 3).

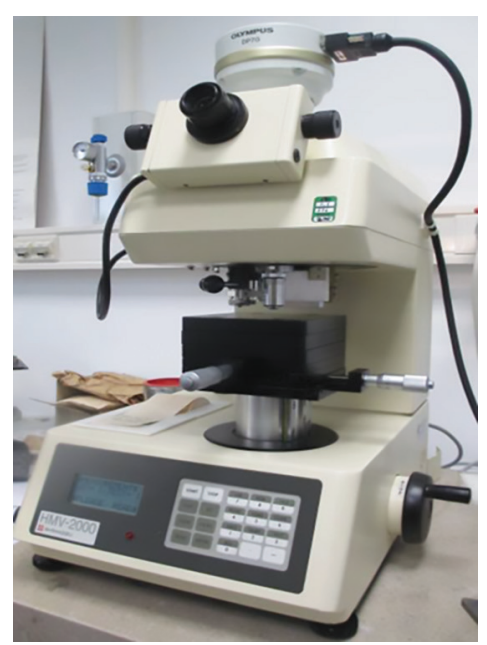

Fig. 2: Micro-hardness tester used in this study 
Group A: Fluor protector varnish application,

Group B: Duraphat varnish application

Group C: Bifluorid 10 varnish application

As per the manufacturer's instruction, a thin layer of varnish was applied with the help of applicator tip with soft-bristle on the blocks of enamel for all three groups. The varnish was removed after 24 hours from all the groups of enamel blocks carefully. The complete removal of varnish was done using acetone-soaked cotton swabs. Finally, the enamel blocks were washed for one minute with deionized water.

\section{Experimental Process}

The process of the experiment was attempted to reproduce the $\mathrm{pH}$ change as in the oral environment, for which the specimens were alternatively treated with a cyclic $\mathrm{pH}$ regimen of demineralization for 3 hours and remineralization for 21 hours daily for a consecutive 6 days.

The immersion of the enamel blocks was done under demineralizing solution for 3 hours $\left(2.2 \mathrm{mM} / \mathrm{L} \mathrm{KH}_{2} \mathrm{PO}_{4}\right.$ $2.2 \mathrm{mM} / \mathrm{L} \mathrm{CaCl}_{2}$, and $50 \mathrm{mM} / \mathrm{L}$ acetic acid, and the $\mathrm{pH}$ were adjusted to 4 with $\mathrm{KOH}$ ). The samples were taken out of the demineralization solution after 3 hours and removed the excess water with the help of blotting paper. Following demineralization, the samples were immersed for 21 hours under remineralization solution (with $\mathrm{pH}$ adjusted at 7, the solution constituted of $1.5 \mathrm{mM} / \mathrm{L} \mathrm{CaCl}_{2}$, $0.9 \mathrm{mM} / \mathrm{L} \mathrm{KH}_{2} \mathrm{PO}_{4}$ and $130 \mathrm{mM} / \mathrm{L} \mathrm{KCl}$ ).

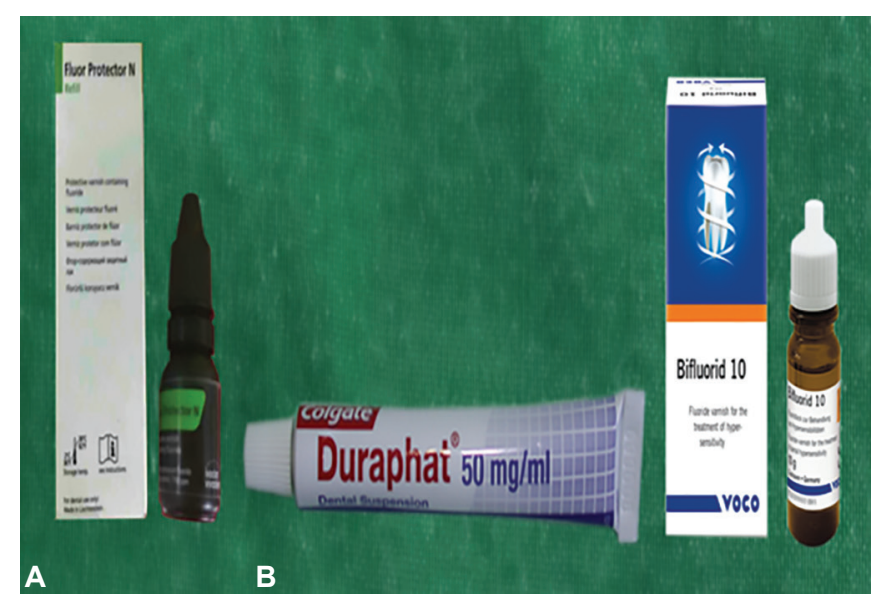

Figs 3 A to C: Materials used in this study. (A) Fluor protector varnish; (B) Duraphat varnish; (C) Bifluorid 10 varnis

Table 1: Enamel surface microhardness values of the three groups before the intervention

\begin{tabular}{lllll}
\hline Varnishes & Mean $\pm S D$ & Std. Error & $F$ & $p$-value \\
\hline $\begin{array}{l}\text { Group A } \\
\text { (Fluorprotector) }\end{array}$ & $230.64 \pm 12.32$ & 0.2441 & & \\
$\begin{array}{l}\text { Group B } \\
\text { (Duraphat) }\end{array}$ & $229.45 \pm 10.22$ & 0.0232 & 28.342 & 0.841 \\
$\begin{array}{l}\text { Group C } \\
\text { (Bi-Fluorid 10) }\end{array}$ & $230.10 \pm 11.45$ & 0.1742 & & \\
\hline
\end{tabular}

\section{Surface Microhardness Testing}

Microhardness tester was used to test the microhardness of the enamel surface with a vickers diamond indenter loaded with $25 \mathrm{mg}$ for about 10 seconds. The average $\mathrm{SMH}$ for each sample was calculated to be five indents. The VHN measurements for the microhardness were made at the baseline, on the 3rd day and 7th day.

\section{Statistical Analysis}

The mean and standard deviation was calculated and analyzed using Statistical Package for the Social Sciences (SPSS) software of version 17.0. For comparison, one-way analysis of variance (ANOVA) was used to measure within and between the fluoride varnishes. The data with the p-value of less than 0.05 was considered to be statistically significant.

\section{RESULTS}

Surface microhardness values of the enamel from three groups before the application were shown in Table 1. The group A showed a slightly more, mean surface microhardness $230.64 \pm 12.32$ when compared to group $B$ with $229.45 \pm 10.22$ and group $C$ with $230.10 \pm 11.45$. There was no significant difference seen from an analysis of covariance between the groups.

Microhardness of enamel surface comparison within different fluoride varnishes on 3rd day was described in Table 2. The group A mean surface microhardness was $235.39 \pm 6.44$, which was slightly higher than that of the baseline values, group B with $231.62 \pm 8.35$ and group C with $233.54 \pm 8.22$. There was no significant difference statistically between the groups.

Microhardness of enamel surface comparison within different fluoride varnishes on the 7 th day is described in Table 3. The group A showed higher mean microhardness value of $262.20 \pm 4.89$, followed by group C with $253.24 \pm 5.10$ and group B with $244.12 \pm 6.65$. The highly significant difference was noted statistically between the groups.

Table 4 describes multiple comparisons of the fluoride varnishes of different types. There was a statistical difference between group A vs group B and between group B vs. group C.

Table 2: Comparison of enamel surface microhardness with different fluoride varnishes on 3rd day

\begin{tabular}{lllll}
\hline Varnishes & Mean $\pm S D$ & Std. Error & $F$ & $p$-value \\
\hline $\begin{array}{l}\text { Group A } \\
\text { (Fluorprotector) }\end{array}$ & $235.39 \pm 6.44$ & 0.0612 & & \\
$\begin{array}{l}\text { Group B } \\
\text { (Duraphat) }\end{array}$ & $231.62 \pm 8.35$ & 0.1537 & 33.263 & 0.8 \\
$\begin{array}{l}\text { Group C } \\
\text { (Bi-Fluorid 10) }\end{array}$ & $233.54 \pm 8.22$ & 0.1229 & & \\
\hline
\end{tabular}


Table 3: Comparison of enamel surface microhardness with different fluoride varnishes on 7 th day

\begin{tabular}{lllll}
\hline Varnishes & Mean $\pm S D$ & Std. error & $F$ & $p$-value \\
\hline $\begin{array}{l}\text { Group A } \\
\text { (Fluorprotector) }\end{array}$ & $262.20 \pm 4.89$ & 0.1018 & & \\
$\begin{array}{l}\text { Group B } \\
\text { (Duraphat) }\end{array}$ & $244.12 \pm 6.65$ & 0.1645 & 38.547 & 0.001 \\
$\begin{array}{l}\text { Group C } \\
\text { (Bi-Fluorid 10) }\end{array}$ & $253.24 \pm 5.10$ & 0.1007 & & \\
\hline
\end{tabular}

\section{DISCUSSION}

The "preventive dentistry" new era has contributed towards the early diagnosis of initial caries. The fluoride efficiency is well documented in the prevention of caries since the 1930s. Topical fluoride application agents have dominated in the past few years in preventing the development of dental caries. ${ }^{9}$ Between the late 1960s to early 1970s varnish containing fluoride were developed to prolong the contact of the fluoride to tooth surface which is lagging in the present topical fluoride applications such as, fluoride mouth rinses and gels. The resin base in the varnish, in which the fluoride is suspended is tenacious towards tooth surface to adhere, which in-turn prolong the interaction of fluoride-enamel overtime. $^{10}$

In this study, in-vitro enamel surface microhardness was evaluated post application of three varnish types and was compared. The microhardness was measured after laboratory simulation of the oral environment using the vickers hardness measuring (VHM) method. The $\mathrm{pH}$ cycling method helps in stimulating the mouth environment by creating acidic challenges in the laboratory. ${ }^{11}$ However, $100 \%$ replication cannot be expected because of the significant and essential factors associated with the process of remineralization such as the salivary speed and flow rate, and its buffering capacity and composition. ${ }^{12}$

The present study focused mainly on the evaluation of micro-hardness of enamel surface after application of different types of fluoride varnishes. Different methods in various studies have been used to access the microhardness of enamel surface; the commonly used tests are the Vickers and Knoop microhardness test. The VHM test uses an instrument which is designed to test rapid microhardness of all shapes and types of nonmetallic and metallic materials. The diamond indenter is used for the indentation's diagonal measurement and its resulting values of hardness. ${ }^{5}$

The enamel is composed of fluorapatite and hydroxyapatite mainly, and delta calcium metaphosphate in traces. The early enamel surface changes are sensitive for the measurement of fluoride efficacy and have the highest anti-caries effectiveness predict value. ${ }^{13}$ The purpose of
Table 4: Multiple Comparisons of different fluoride varnishes using Tukey's post hoc test

\begin{tabular}{llll}
\hline Groups & Compared with & Mean difference & Sig. \\
\hline \multirow{2}{*}{ Group A } & Group B & 18.08 & 0.001 \\
& Group C & 8.96 & 0.08 \\
\multirow{2}{*}{ Group B } & Group A & -18.08 & 0.001 \\
& Group C & -9.12 & 0.04 \\
Group C & Group A & -8.96 & 0.07 \\
& Group B & 9.12 & 0.02 \\
\hline
\end{tabular}

the varnish is to retain and prolong the fluoride's close contact with the tooth surface.

Featherstone et al. ${ }^{14} \mathrm{pH}$ cycling protocol was followed in this study as described. This protocol is a modified protocol which was used on human enamel, which was proposed by Ten Cate and Duijsters. ${ }^{15}$ This model simulates a high-risk caries condition in vivo. This model simultaneously measures the remineralization enhancement and demineralization inhibition and their net results. The dynamic demineralization and remineralization cycles are simulated by immersion of the enamel specimens in the acidic solution for demineralizing and supersaturated buffer solution for remineralization sequentially. These solutions for demineralization and remineralization approximate with the supersaturation and mineral ion composition of saliva as reported by ten Cate and Duijsters originally.

The present study showed that the demineralization inhibitory effect of Fluor protector was slightly higher than that of Bifluorid 10. The study by Munshi et al. ${ }^{16}$ showed that an increase in the content of the minerals after the application of two fluoride varnishes may be responsible to obtain higher VHN values in both the experimental groups. The fluor hydroxyapatite and fluorapatite formation could be the probable reason for the fluorapatite to be harder and more acid resistant dissolution than hydroxyapatite.

In the present study, significantly higher SMH was seen in Fluor Protector compared to Biflourid 10 varnish. This result may be due to the formation of amount and type of $F$ compound on the enamel surface. The high viscosity of Bifluorid 10 varnish makes it better adherent to demineralized areas than tooth surface which is intact, compared to FPV, as similar to the result of the study by Pinar Erdem et al. ${ }^{17}$ However, fluor protector containing "polyurethane-based compound difluorosilane" forms a transparent thin film that easily adheres on the intact surface of the tooth.

Even though Biflourid 10 gives more soluble fluoride when compared with FPV, the result shows that maximum amounts of fluoride are formed and retained on the enamel treated with fluor protector. This retained fluoride may be released during the cariogenic challenge 
and may spread into the enamel and reduce the caries lesion progress, propitiate the reprecipitation of less soluble calcium phosphate. ${ }^{5}$

Duraphat showed the least SMH value from the present study. The study by Attin et al. ${ }^{18}$ showed that fluoride is released from Duraphat ${ }^{\mathrm{TM}}$ topical application during the experimental period. From the study conducted by Delbem et al. ${ }^{19}$ showed that the retained $\mathrm{CaF}_{2}$ was higher than formed $\mathrm{CaF}_{2}$ in the placebo groups. The $\mathrm{pH}$ cycling model had a high acid challenge, attributed to use in the present study. As demineralization of the enamel increases, the enamel becomes more reactive which could facilitate deposition of fluoride from the solution, though the concentration of fluoride was low.

Fluoride varnishes increase the hardness of enamel surface to form a reservoir to the underlying apatite crystallites and act by a slow release of fluoride ions to form a more stable complex which hampers crystalline dissolution. The rate of demineralization will get reduced and also increases calcium fluoride deposits. This depends on the type and amount of fluoride compound formed on the enamel surface. In the present study, Fluor Protector Varnish increases the enamel surface microhardness, because it contains $1.0 \%$ difluorosilane, polyurethane varnish base with ethyl acetate and isoamyl propionate solvents. The fluoride component is equivalent to $0.1 \%$, or $1000 \mathrm{ppm}$ in solution. As the solvents evaporate, the fluoride concentration at the tooth surface increases to a much higher value. And in this study, we found that there was a significant difference between the three fluoride varnishes on enamel surface microhardness hence null hypothesis was rejected and an alternative hypothesis was accepted.

The study was conducted under in-vitro condition, therefore; the result may be different from the dynamic process occurring in the in vivo situation. Hence, there is a necessity to conduct in vivo studies to validate the current study result.

\section{CONCLUSION}

In conclusion, the application of FPV increases the enamel surface microhardness compared to Duraphat and Bifluorid 10 varnishes.

\section{REFERENCES}

1. Johansson I, Holgerson PL, Kressin NR, Nunn ME, Tanner AC. Snacking habits and caries in young children. Caries Res. 2010;44:421-430.

2. Rao SK, Bhat GS, Aradhya S, Devi A, Bhat M. Study of the efficacy of toothpaste containing casein phosphopeptide in the prevention of dental caries: a randomized controlled trial in 12- to 15-year-old high caries risk children in Bangalore, India. Caries Res. 2009;43:430-435.
3. Tajer DM and Al-Obaidi WA. Dental caries and salivary Interleukin-6 among preterm postpartum women in relation to baby birth weight (Comparative study). J Bagh College Dentistry 2013;25(Special Issue 1):174-177.

4. Zero DT, Fontana M, Martínez-Mier EA, Ferreira-Zandoná A, Ando M, González-Cabezas C, and Bayne S. The biology, prevention, diagnosis and treatment of dental caries Scientific advances in the United States. JADA.2009; 140(9 suppl):25S-34S.

5. Doddamani GM, Girish Babu KL. Effect of Fluoridated Varnishes on surface micro-hardness of Enamel. Int J Oral Health Med Res 2017;4(2):1-3.

6. Delbem ACB, Bergamaschi M, Sassaki KT, Cunha RF. Effect of fluoridated varnish and silver diamine fluoride solution on enamel demineralization: $\mathrm{pH}$-cycling study. J Appl Oral Sci. 2006;14(2):88-92.

7. Beltrán-Aguilar ED, Goldstein JW, Lockwood SA. Fluoride varnishes. A review of their clinical use, cariostatic mechanism, efficacy and safety. J Am Dent Assoc. 2000;131(5):589-596.

8. Lata S, Varghese NO, Varughese JM. Remineralization potential of fluoride and amorphous calcium phosphate-casein phospho peptide on enamel lesions: An in vitro comparative evaluation. J Conserv Dent. 2010;13(1):42-46.

9. Strohmenger L, Brambilla E. The use of fluoride varnishes in the prevention of dental caries: A short review. Oral Dis 2001;7:71-80.

10. Majithia U, Venkataraghavan K, Choudhary P, Trivedi K, Shah S, Virda M. Comparative evaluation of application of different fluoride varnishes on artificial early enamel lesion: An in vitro study. Indian J Dent Res 2016;27:521-527.

11. Casals E, Boukpessi T, McQueen CM, Eversole SL, Faller RV. Anticaries potential of commercial dentifrices as determined by fluoridation and remineralization efficiency. J Contemp Dent Pract. 2007;8(7):1-10.

12. Molaasadolah F, Eskandarion S, Ehsani A, Sanginan M. In Vitro Evaluation of Enamel Microhardness after Application of Two Types of Fluoride Varnish. J Clin Diagn Res. 2017;11(8): ZC64-ZC66.

13. Subramaniam $P$, Telegeti S. Effect of different concentrations of fluoride varnish on enamel surface microhardness: An in vitro randomized controlled study. J Indian Assoc Public Health Dent 2016;14:344-347.

14. Featherstone JDB, O Reilly MM, Shariati M, Brugler S. Enhancement of remineralization in vitro and in vivo. In: Leach SA. Factors affecting de- and remineralization of the teeth. Oxford: IRL Press; 1986:23-34.

15. Ten Cate JM, Duijsters PPE. Alternating demineralization and remineralization of artificial enamel lesions. Caries Res 1982;16:201-210.

16. Munshi AK, Reddy NN, Shetty V. A comparative evaluation of three fluoride varnishes: An in vitro study. J Indian Soc Pedod Prev Dent 2001;19:92-102.

17. Pinar Erdem A, Sepet E, Kulekci G, Trosola SC, Guven Y. Effects of two fluoride varnishes and one fluoride/chlorhexidine varnish on Streptococcus mutans and Streptococcus sobrinus biofilm formation in vitro. Int J Med Sci 2012;9:129-136.

18. Attin T, Hartmann O, Hilgers RD, Hellwig E. Fluoride retention of incipient enamel lesions after treatment with a calcium fluoride varnish in vivo. Arch Oral Biol. 1995;40:169-174.

19. Delbem AC, Brighenti FL, Oliveira FA, Pessan JP, Buzalaf MA, Sassaki KT. In vitro assessment of an experimental coat applied over fluoride varnishes. Journal of Applied Oral Science. 2009 Aug;17(4):280-283. 